\title{
The Dimensions of Identities and its Roles in Shaping Teachers' Effectiveness
}

\author{
Fariza Khalid (PhD) \\ The National University of Malaysia \\ Email: fariza.khalid@ukm.edu.my
}

\section{Doi:10.5901/mjss.2015.v6n3s1p306}

\begin{abstract}
Teachers' effectiveness and commitment towards their job are related to the way they value their significance and professionalism. In other words, the way teachers value themselves is related to their professional identities. This research was conducted to examine the nature of teachers' dimensions of identities and how these dimensions interconnected to each other in determining teachers' effectiveness. Research participants were 20 teachers, ranging from new to senior teachers from ten secondary schools. Data was generated through one-to-one interviews. The analysis of data was conducted using thematic analysis. The findings showed the emergence of four main dimensions of teachers' identities. This paper explained in details the influences of these sets of identities on teachers' effectiveness.
\end{abstract}

Keywords: Teachers' identities, effectiveness, professional identities, learners' identities, personal identities, members of communities' identities

\section{Introduction}

The importance of exploring teachers' identities and how these identities influence their effectiveness is emphasised by researchers for example Day et al. (2004) and Sisrankulwong (2005) who highlighted the relationship between teachers' professional commitment and their professional identity. Identity is defined as 'what makes you similar to yourself and different from others' (Deschamp and Devos 1998, p. 3). Meanwhile, Beijaard et al. (1995, p. 282) value identity as 'who or what someone is, the various meanings someone can attach to oneself or the meaning attributed to oneself by others'. Day (2004), however, focuses more on a professional perspective in terms of an individual's self-image and how they relate themselves to their profession and surrounding factors:

Who and what they are, their self-image, the meanings they attach to themselves and their work, and the meanings that are attributed to them by other - are, then associated with both the subject they teach, their relationships with the pupils they teach, their roles and the connections between these and their lives outside school. (p. 53)

In addition to the way identity is defined, the concept of identity can also be viewed through different categories. For instance, Burk and Stets (2009) define three types of identity: person identity, role identity and social identity. Personal identity refers to the set of meanings defining a person as a unique individual. Role identity refers to the internalised meaning of a role, or the set of expectations tied to a social position and guiding the attitudes and behaviours that individuals apply to themselves. The role identity of professor, for instance, may include the meanings of 'researcher' and 'teacher' that a person applies to him or herself when playing the role of a professor. Social identity is defined as based on a person's identification with a social group. Burk and Stets (2009) further explain that although identities differ in their bases, they operate simultaneously in different situations. Responding to this, Esther (2011) gives an example: 'A teacher is a part of a specific school (social identity), functions as a teacher within that school (role identity) and fulfils this role in his or her own way (person identity)' (p. 5). Identity as explained by Esther (2011) can therefore be viewed as a product as well as a process which occurs through the influence of external and internal factors.

Day et al. (2007), on the other hand, classify identity into three categories: professional, situated and personal identities. Professional identity, according to Day et al. (2007), is 'open to the influence of long-term policy and social trends as to what constitutes a good teacher, classroom practitioner etc.' (p. 107). Professional identity from this perspective covers a teacher's role, responsibilities, workload, CPD and policy. Situated identity, according to Day et al. (2007), is located within a specified school, department or classroom and is 'affected by pupils, support and feedback loops from teacher's immediate working context which is connected to long-term identity' (p. 107). The third category is personal identity, which is based on life outside of school, and covers teachers' identities as fathers, mothers, sons and so on. Day et al. (2007) also posit that personal identity can cause tensions for individuals and may become a hindrance to their effectiveness. 
An overall observation from the literature suggests that dimensions of identities still remain debatable. As stated earlier, researchers had different ways of looking at teachers' identities (Day et al., 2007; Burk and Stets, 2009) and previous research had been done in other countries, e.g., United Kingdom. Therefore this research was conducted to identify the dimensions of teachers' identities in the context of Malaysian education and to investigate how these sets of identities affect teachers' effectiveness.

\section{Research Objectives}

The research objectives of this research are to identify the dimensions of teachers' identities and to explain how do these dimensions of identities interconnect to each other in shaping teachers' effectiveness.

\section{Methodology}

This research employed a case study approach, which aims to focus on the relationships and processes involved in the case being studied. Denscombe (2010) postulates that in order to understand one thing it is necessary to understand many others and, crucially, how the various parts are linked. Case study approach offers chances for the researcher to go into sufficient detail to unravel the complexities of a given situation. Therefore, it has been critical for me to look at those interrelationships and the processes of how teachers' identities influenced each other (for example, how their personal identities influenced their perceived importance, and then how their value of themselves impacted upon their identities as a member of communities etc).

Research participants were 20 teachers ( 15 female, 5 male) from ten high performing secondary schools. The selection of the participants was done through purposive sampling, where teachers were selected based on their years of teaching experiences, i.e., from new teachers to senior teachers. Data was generated through in-depth one-to-one interviews. For each participant, not less than three interviews were conducted which lasted for about an hour. Interview data was recorded and turned into verbatim.

The analysis involved was a thematic analysis (Braun and Clarke, 2006), which allows for careful analysis in finding coherent and distinctive themes. The coding process was done in parallel with the phases of data generation, and the files were transferred and coded based on the chronology of the phases themselves. While reading the transcripts, I tried to relate the answers to my research question. However, I also allowed for the progressive emergence of new and related concepts (Miles and Huberman, 1994).

\section{Findings}

This research aimed to identify the dimensions of teachers' identities and how these identities affect teachers' effectiveness. Based on the analysis done, four main elements of identities emerged, namely: personal identities, professional identitites, learners' identities and member of communities' identities as discussed in the next sections.

\subsection{Personal identities}

The first emerging theme was teachers' personal identities. This category of identities covered four sub-categories, namely their age, gender, marital status number of children and the age of their children.

Table 1. Sub-categories of teachers' general identities

\begin{tabular}{|c|c|c|c|}
\hline Categories & Codes & Sub-categories & Description \\
\hline \multirow{4}{*}{ Personal identities } & AGE & Age & Teachers' age. \\
\cline { 2 - 4 } & GEN & Gender & Teachers' gender. \\
\cline { 2 - 4 } & MS & Marital status & Teachers' marital status. \\
\cline { 2 - 4 } & NOC & Number of children & Teachers' number of children and their age. \\
\hline
\end{tabular}

From the analysis, teachers' ages was seen as related to their professional identities, i.e., their sense of commitment, satisfaction and commitment towards their job. Younger teachers with younger children showed less commitment to spend extra time in school as they claimed to have to rush home as soon as school hours ended. Older teachers on the other hands, did not feel any urgency to do so as most of their children had grown up and some of them were studying 
abroad, therefore, they did not have much difficulty to spend more time in school. Teachers' age was related to their number and the age of their children. It was also observed that female teachers showed more needs to spend their time with children as compared to male teachers.

\subsection{Professional identities}

The second emerging theme was teachers' professional identities. The categories that constitute this theme are: responsibilities in school, competency in teaching, competency in using IT, perceived importance, job satisfaction, commitment and motivation. Table 2 shows the detailed findings.

Table 2. Sub-categories of teachers' professional identities

\begin{tabular}{|c|c|l|l|}
\hline Categories & Codes & Sub-categories & Description \\
\hline \multirow{5}{*}{ Professional identities } & PLF & Professional life phase & Teachers' years of teaching experiences. \\
\cline { 2 - 4 } & RIS & Responsibilities in school & Teachers' responsibilities in school. \\
\cline { 2 - 4 } & CITL & Competency in teaching & $\begin{array}{l}\text { The way teachers perceived their competency in conducting } \\
\text { teaching activities and other related skills. }\end{array}$ \\
\cline { 2 - 4 } & CIIT & Competency in using IT & $\begin{array}{l}\text { The way teachers perceived their skills in using IT in teaching } \\
\text { and daily work. }\end{array}$ \\
\cline { 2 - 4 } & JS & Job satisfaction & $\begin{array}{l}\text { How the teachers perceived their importance in school. } \\
\text { contribution. }\end{array}$ \\
\cline { 2 - 4 } & COM & Commitment & $\begin{array}{l}\text { How much commitment and time teachers gave for their } \\
\text { teaching-related tasks. }\end{array}$ \\
\cline { 2 - 4 } & MOT & Motivation & Teachers' motivation to become a teacher. \\
\hline
\end{tabular}

The categorisation of teaching experience used in this research was adopted from the Six Professional Life Phases identified by Day et al. (2007) which consists of: 0-3 years, 4-7 years, 8-15 years, 16-23 years, 24-30 years and more than 30 years of teaching experience. The next sub-category was teachers' responsibilities in school, which covered the age of students, subject teachers were teaching, and their tasks in schools. In general, teachers' extra tasks fell into three main categories: administration, curriculum and co-curriculum. Co-curriculum activities include involvement in sports and games, societies and clubs, uniformed bodies and other relevant activities decided by the Ministry of Education. Examples of teachers' tasks are: 'advisor for student organisation', 'advisor for student sports clubs', form teachers, secretaries of their Subject Panel, Expert Teachers, senior assistant, Education Management Information System (EMIS) data teacher, and Information Technology Coordinator (ITC).

Competency in teaching involves pedagogical aspects such as the way teachers conduct the activities in their lessons, how they control their classes and the extent to which they have mastered the subject(s) they teach. Another competency involved in the analysis was the teachers' perception of their skills in using ICT. Perceived importance refers to how the teachers perceived their importance to their schools, students or colleagues. For example, a feeling of being important can be seen in whether teachers felt that they had given a significant contribution by helping students to excel in their academic performance or through their involvement in activities that gave credit to their school's name. Other teachers saw their importance in terms of their contribution to other teachers by sharing their knowledge and techniques used to produce better results in classroom activities. Under this category was teachers' satisfaction and commitment towards their job.

Motivation refers to what motivated the teachers to become teachers in the first place and to remain in the teaching profession. Other factors stated were friends, the subject, the nature of working hours, former teachers and economic status.

\subsection{Learners' identities}

The next category of teachers' identities is teachers as learners. The teachers' learners' identities covered: aspects to be improved; professional development courses they had attended; and teachers' learning preferences. Table 3 shows the findings. 
Table 3. Sub-categories of teachers' learners' identities

\begin{tabular}{|c|c|l|l|}
\hline Categories & Codes & Sub-categories & Description \\
\hline \multirow{4}{*}{ Learners' identities } & NFI & Needs for improvements & The aspects that teachers' need to improve. \\
\cline { 2 - 4 } & APD & Attended professional development & Professional development they had attended \\
\cline { 2 - 4 } & LP & Learning preferences & $\begin{array}{l}\text { How teachers view the most effective learning } \\
\text { experience approach for their professional } \\
\text { development. }\end{array}$ \\
\hline
\end{tabular}

From the analysis, teachers shared their needs for improvement in many areas, which covered many elements of teaching and learning. The most cited area was pedagogic skills, followed by social relationships or interpersonal relationships and emotional intelligence. Pedagogic skills cover aspects such as planning, assessment and classroom management.

The professional development in this case includes any six hours of courses, workshops, professional talks, seminars or in-house training courses, as well as professional days. In terms of ICT-related training, the findings show that the majority of the teachers had attended various ICT-related courses that were conducted internally, followed by courses outside school. Under the category of pedagogic or subject-based training, courses mentioned included effective teaching and learning, subject-specific courses (e.g. English, mathematics and physics) and a course on teaching mathematics and science in English. Besides these two main categories, the 'other' category included courses such as leadership, examination paper marking, induction, photography and video authoring.

Learning preferences refers to how teachers perceived they learned best, i.e., what teachers viewed as the most effective learning approach for their professional development. From the analysis, two main categories emerged: formal and informal approaches for teachers' professional development. The formal approach includes in-house and outside training, while informal refers to teachers' groups or communities in which they learn from each other (Ganser, 2000). Overall, majority teachers preferred informal learning through communities or teams in their current schools. Two teachers preferred formal training, while seven teachers believed that the most effective approaches for their professional development included both formal (in-house and outside training) and informal learning from colleagues.

This finding shows that both forms of professional development (formal and informal) have an impact on teachers' professional development, but in different ways. The data indicate that teachers valued formal training as a platform for them to learn new skills, involving, for example, new theories or the use of technological innovations. However, informal learning through discussions and exchanging experiences and knowledge enabled teachers to implement these theories or carry out their tasks more efficiently.

The data also show that learning from each other, especially those who teach the same subject, was perceived as being useful to help teachers to become more effective and skilled (Sarah-Interview1, Aini-Interview1). This suggests that informal learning, particularly in face-to-face situations, was something that the teachers valued. In informal learning, the teachers deal with understanding and exchanging tacit knowledge (Sarah-Interview2, Fariha-Interview2, KathyInterview2, Sham-Interview3). In other words, their learning and practice occurs in phases. The initial phase involves their learning about certain skills (normally obtained through formal training or courses), and the next phase involves their practice of these skills, as well as learning through doing and talking about issues. This happened within teachers' existing communities, some of them using the terms 'Subject Panel' or 'colleagues'.

\subsection{Member of communities' identities}

Two main sub-categories under teachers' identities as members of communities are their current membership in communities, and how they perceive their roles as members of these communities. Table 4 shows the overall findings.

Table 4. Sub-categories of teachers' members of communities' identities

\begin{tabular}{|c|l|l|l|}
\hline \multicolumn{1}{|c|}{ Categories } & Codes Sub-categories & Description \\
\hline \multirow{2}{*}{ Members of communities' identities } & MOC & Membership in communities & $\begin{array}{l}\text { The communities (or groups or teams) that } \\
\text { teachers had already been involved in their } \\
\text { daily work. }\end{array}$ \\
\cline { 2 - 4 } & PR & $\begin{array}{l}\text { Perceived roles as members of } \\
\text { communities }\end{array}$ & $\begin{array}{l}\text { How teachers perceive their roles as members } \\
\text { of communities. }\end{array}$ \\
\hline
\end{tabular}


From the findings, there are at least eight groups or communities emerging from the analysis (Khalid, 2013). Among the communities, the most cited one was the Subject Panel, followed by their membership of the social network like Facebook, then form teachers' community. Other communities emerged form the analysis examiners, Expert Teachers, Information Technology Coordinators (ITCs), and PhD groups. This dimension of identities also covered how teachers perceived their roles as members of communities; which can be seen in the form of whether they felt themselves as important contributors to their communities or as receivers.

\subsection{The interconnections between the dimensions of teachers' identities}

To illustrate the interconnections between the dimensions of teachers' identities, I developed a causal network (Miles and Huberman, 1994), which later named 'potential network' (Figure 1). The basic principle in this process is to develop one or more meta-networks that respect the individual case networks from which they have been derived. The outcome of this process is a potential causal model, i.e., 'a network of variables with causal connections among them, drawn from multiple-case analysis' (Miles and Huberman, 1998, p. 222). It is a higher order effort to derive a testable set of propositions about the complete network of variables and interrelationships. To do this, we put the related factors in boxes, and these boxes led to other boxes through 'streams' (Miles and Huberman, 1994). The streams all led to the final outcome (for this research, the final outcome is teachers' effectiveness).

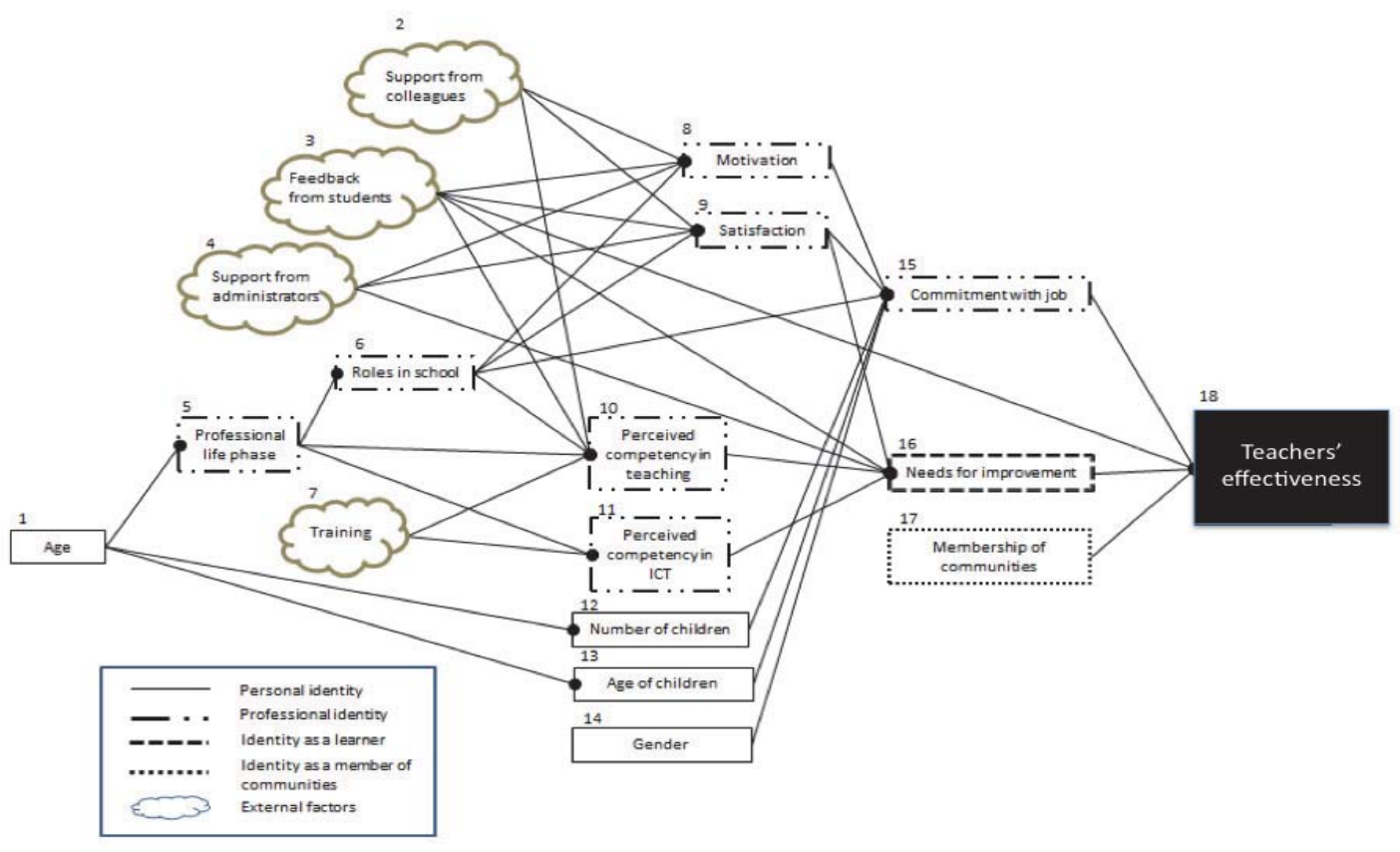

Figure 1. The interconnections between the dimensions of teachers identities

In streams 1-5-6-8-15-18 and 1-5-6-9-15-18, it can be seen that teachers' ages related to their professional life phases, and that their professional life phases in turn determined what roles or positions the teachers had in their schools. The higher the phase of their professional life, the more important roles the teachers had in their schools. The teachers' sense of motivation to improve and to become more efficient increased when they felt that they had an important role in their schools, and this was found to be accompanied by greater job commitment. One manifestation of that commitment was teachers taking part in formal and/or informal professional development.

Apart from teachers' roles in their schools, other external factors also contributed to teachers' levels of motivation and satisfaction with their jobs, as shown in streams 2-8-15-18, 2-9-15-18, 3-8-15-18, 3-9-15-18, 4-8-15-18 and 4-9-1518. Three main external factors identified from the analysis were: support from colleagues, feedback from students and support from school administrators. These factors were also found to influence how teachers perceived their competency in teaching (streams 2-10-16-18 and 3-10-16-18). It appears that the teachers perceived themselves as more competent when they received positive feedback from their students, telling them that they had been great teachers. At the same time, feedback from students could influence teachers' needs for improvement (stream 3-16-18). When teachers felt that 
their students were not satisfied with the way in which they conducted their classes, their needs to improve grew larger. In addition, teachers' perceived competency was also influenced by how their principals acknowledged them (stream 3-10). For some teachers, this could also be related to their increasing needs to improve, and therefore, when they had a chance to attend any form of training they would do so, as well as involving themselves in teachers' groups or communities such as the Subject Panel. These findings suggest that the influence of colleagues, students and administrators are important contributors to the formation of teachers' professional identities in Malaysia, similar to teachers from other parts of the world that have been involved in previous studies.

Streams 1-5-10-16-18 and 1-5-10-17-18 show that the teachers' perceived competency in teaching and in ICT were related to their professional life phase. More senior teachers had higher perceptions of their teaching competency as compared to newer or younger teachers. However, in terms of perceived competency in ICT, the findings show that newer teachers had higher perceived competency compared to more senior teachers. In addition, an external factor (streams 7-10 and 7-11), i.e. attendance at relevant training, also determined how teachers perceived their competency in teaching and ICT. Teachers who had attended more ICT-related training felt more confident in their competency in both teaching and ICT.

Teachers' perceived competency in teaching and ICT was found to be associated with their need for improvement, their perceived role in the community and, finally, how they participated in their formal and/or informal professional development. The findings show that there was an association between perceived competence and their perceived need for improvement, i.e. less competent teachers felt greater a need for improvement, and vice versa; also, the more they felt themselves competent, the greater was their sense of having a role in their community. Therefore, in this study, teachers' participation in formal and/or informal professional development could be related to the level of their need for improvement as well as their perceived role in their communities. It was also found that teachers' perceived roles in their communities were associated with their perceived competency. The findings show that teachers with higher opinions of their competence had more confidence about their effectiveness.

\section{Discussions and Conclusions}

From the overall findings, all the categories of teachers' general identities seemed to be related to each other. Personal identities entail teachers' personal backgrounds, i.e. their age, gender, marital status and number of children, their children's ages and how the teachers see themselves as people. The analysis reveals that the way in which teachers see themselves and their commitment to their jobs is partly impacted by their personal identities; as Day et al. (2007) posit, our personal identities can affect the way we see ourselves (self-image), and the way we behave influences the way we identify ourselves in terms of our jobs, our personal goals and how we see ourselves in relation to others (Beijaard, 2006). This finding also corroborates other research that shows how teachers' personal identities have a great influence on their professional identities, e.g. Nias (1989).

Teachers' gender, their number of children and the children's age were found to influence teachers' commitment, particularly in terms of the time they spent on teaching-related work. This is in line with Maurer and Tarulli (1994), who state that events in teachers' lives outside school such as family commitments can both positively and negatively influence teachers' motivation and commitment to their job. Teachers with children who were in primary school (aged between birth and 12) were more concerned with taking care of their children after school hours. This finding is in line with Ahmad (2008), who states that teachers who had more responsibilities in their families would prioritise their families over school work. Although all teachers in this study were married, the number and age of their children were seen as more influential on female teachers than on male teachers. Female teachers were more concerned with giving their commitment to and taking up responsibilities for their children and other family members, e.g. their mothers (for those who lived in an extended family where the grandmother stayed with their children and grandchildren). This scenario was found to be more critical for those who had younger children, i.e. between birth and 12 years old, as at this stage, children need more attention and guidance compared to older children (Khalid et al., 2014). In comparison, for teachers whose children were 18 years and above, the feeling of needing to rush home to the family was not that critical, as their children could take care of themselves.

The next category, teachers' professional identities, covers what Day (2004) names as aspects of teachers' professional identities: the subject teachers were teaching, their roles in school, and their relationships with their students (which closely relates to the development of teachers' self-image and competency). The categories in this finding are also in line with Beijaard (2006), who states that teachers' identities cover how they identify themselves in terms of their job, their personal goals and how they see themselves in relation to others.

In this research, teachers' roles and responsibilities were partly found to be associated with their years of being in 
the teaching profession or their professional life phase. The teachers in a higher professional life phase, e.g. 4 to 7 years and 8 to 15 years, took on more important roles and positions in their schools, compared to newer teachers or those in the early professional life phase, e.g. 0 to 3 years. This implies that teaching experience was important for these teachers to gain credibility and therefore to be given more important responsibilities by their school principals (Khalid et el., 2013). This finding corroborates Day et al. (2007), who find that starting from four years of teaching experience, teachers have a greater workload and more responsibilities, which affect their perceived identities, motivations and sense of effectiveness. In relation to this, the findings also reveal that teachers with more important roles in their schools developed a greater sense of importance compared to teachers with fewer years of teaching experience and less important roles in their schools.

The teachers' perceived importance influenced the way that they valued their jobs. The findings reveal that the teachers' perceived importance affected their satisfaction regarding their teaching job, as well as their motivation to be a better teacher. It seems that for most of the teachers, the more responsibilities they held in their school, the more selfesteem they had. Therefore, their level of motivation and sense of importance and significance became higher, and as a result they gained more satisfaction from their contribution to their schools in general and to their students in particular. Day et al.'s (2007) findings suggest that teachers in a higher professional life phase are more likely to face conflicts in their work due to greater responsibilities and workloads, which could affect their effectiveness. The findings in this study show that, the heavier their responsibilities, the greater the teachers' status, and therefore, the higher their level of selfesteem, resulting in greater commitment to teaching.

Teachers' commitment was closely linked to their motivation and satisfaction with their jobs. Their satisfaction and motivation, in turn, were closely linked to other factors, i.e. good relationships with students, colleagues and school administrators. They obtained satisfaction when they felt appreciated by students. This was mentioned by almost all the teachers in this study regardless of what phase of professional life they were in, and this follows other researchers (Day et al., 2007; Sutton, 2000) who assert that job satisfaction is one of teachers' positive emotions that have an influence on their commitment, in turn enhancing their contributions to the organisation of their school. Overall, this shows that, apart from their personal commitment to their families, teachers' motivation, satisfaction and their role in their schools were also found to influence teachers' commitment towards their jobs.

Another sub-category of teachers' professional identities is their perceived competency in teaching and in using ICT. Related to this, teachers' professional life phase once again emerged as an influential factor. The findings indicate that teachers in the higher professional life phase groups had more self-confidence in teaching; their learning process resulted in the teachers feeling that they had increased their teaching competency, not only in terms of content, but also in terms of pedagogical and interpersonal skills. Conversely, teachers in early professional life phases, perceived themselves as lacking confidence to face the students due to their lower pedagogical skills. It was also found that teachers in the earlier professional life phase ( 0 to 3 years) were struggling to handle their students and to master the syllabus.

With regard to teachers' competency in ICT, the findings indicate that although teachers with more teaching experience felt more competent in teaching and pedagogical skills, many of them found themselves lacking in ICT skills. Newer teachers, on the other hand, had been trained in more ICT-related basic skills, following the Ministry's initiatives, i.e. to provide teachers with more ICT skills so as to produce more ICT-competent teachers. Even so, their level of competency in ICT did not guarantee better integration of ICT into their teaching.

Another category is teachers' identities as learners, which entails teachers' conceptions of professional development, covering the professional development approach/es they preferred and the aspects they wanted to improve. Since the participating teachers in this study varied in terms of their professional life phase and the positions they held in their schools, this resulted in differences in terms of their perceived competency in teaching and using ICT, as well as differences in the aspects that they wanted to improve. The findings indicate that newer teachers cited more aspects for improvement as compared to more senior teachers. This indicates different needs of teachers in different phases of professional life, and has implications for the nature of any communities that would be useful to teachers. In relation to this, Hopkins (1996) emphasises that successful teachers' professional development should not use a onesize-fits-all approach, but should instead consider the different needs of different teachers.

In relation to teachers' learning preferences, the findings suggest that the majority of teachers valued informal learning more than formal learning. It emerged from the teachers' explanations that their involvement in informal exchanges of ideas provided them with more tacit knowledge, such as 'untold rules of thumb', specific perceptions or underlying assumptions (Lave and Wenger, 1998). However, the teachers did not deny the importance of attending formal professional development courses such as in-house training that gave them more explicit knowledge and concrete skills, such as learning to use new applications or manuals. This supports Wenger et al. (2002), who state that sharing 
activities for professional development should be viewed from both perspectives; similarly, Liao (2003) stresses that professional development should cover not only explicit knowledge but also tacit knowledge, as both are required to do the job more effectively. Although the findings reveal that teachers preferred informal learning through teachers' communities in or outside their schools, the tension was evident for them when engaging with wider practice, i.e. sharing with teachers from other schools. As a result, their communities could not go further than the teachers' schools. When teachers were involved in online communities of practice (CoPs) across schools, many issues arose.

The last category is teachers' identities as members of communities. The findings reveal that participating in CoPs was not something new to the teachers. Many of them were currently engaging with certain communities, either within their current schools or outside their schools. However, not many participated in online communities. The majority cited their involvement in Subject Panels (SPs): they did not use the term 'community', but their description of how the SPs worked and how they shared their practices and knowledge fitted a community of practice model. Being part of such communities helped the teachers to develop their competencies as well as their self-image and self-esteem. Teachers who had been involved in such communities claimed to have more self-confidence and security as they had support from other colleagues; this was especially the case for new teachers who still had difficulty in choosing appropriate approaches in their classes. Having support and access to ideas from senior teachers helped them to design their teaching better. At the same time, experienced teachers also developed their self-esteem through their participation in their own communities of practice.

The findings indicate that teachers obtained more support related to their profession through their participation in other communities. Teachers in this study were involved not only in profession-based communities, e.g. Subject Panels, form teachers' communities or Expert Teachers' communities, but also in more social communities, particularly via online platforms such as Facebook. Hargreaves and Goodson (1996) believe that teachers' learning involves both intellectual and emotional processes that will not only enrich their knowledge and practice, but also their self-efficacy, confidence and commitment. Aside from two teachers, all of the teachers were Facebook users, although their level of participation in this network varied. The majority spent their time sharing things that were not directly related to their jobs, as if this was the channel through which they could escape from thinking and worrying about their jobs for a while, e.g. Kathy-Interview1.

Overall, it can be concluded that the dimensions of teachers' identities as emerged from the analysis in this study are closely interrelated to each other. Apart from personal identities nad professional identities, an additional dimension proposed through the findings of this research is teachers' identities as members of communities. Teachers seemed to learn from each other to improve their practices. Therefore, this dimension of identities should be put into consideration in understanding more about teachers' effectiveness the mian purpose of teachers' communities were to help each other achieve their goals as well as their school's goals, and to become better practitioners.

\section{References}

Ahmad, A. (2008). Job, family and individual factors as predictors of work-family conflict. The Journal of Human Resource and Adult Learning, 4 (1), 57-65.

Aubusson, P., Steele, F., Dinham, S., \& Brady, L. (2007). Action learning in teacher learning community formation: informative or transformative? Teacher Development, 11.2 (2007), 133-148.

Beijaard, D. (2006, December). Dilemmas and conflicting constraints in teachers' professional identity development. Paper presented at the EARLI SIG Professional Learning and Development Conference, Open University of the Netherlands.

Beijaard, D., Beijaard, N., Verloop, T., \& Vermunt, J.D. (1995). Teachers' perceptions of professional identity: an exploratory study from a personal knowledge perspective. Teaching and Teacher Education (16), 749-64.

Braun, V., \& Clarke, V. (2006). Using thematic analysis in psychology. Qualitative Research in Psychology, 3 (2), 77-101.

Burk, P. J., \& Stets, J. E. (2009). Identity theory. New York: Oxford University Press Inc.

Day, C. (2004). A passion for teaching. London: Routledge Falmer.

Day, C., Sammons, P., Stobart, G., Kington, A., \& Gu, Q. (2007). Teachers Matter. New York: Open University Press.

Denscombe, M. (2010). The Good Research Guide for small scale research projects (4th ed.). Buckingham: Open University Press.

Deschamps, J. C. and Devos, T. (1998). Regarding the relationship between social identity and personal identity. In Worchel, S., Francisco M. J., Pa'ez, D., \& Deschamps, J. C. (Eds.). Social Identity: International perspectives (pp. 1-12). London: SAGE Publications.

Esther, T. C. (2011). Teachers' sense of their professional identity (Unpublished doctoral dissertation). University of Groningen, Netherlands.

Ganser, T. (2000). An ambitious vision of professional development for teachers. NASSP Bulletin, 84 (618), 6-12.

Goodson, I. F., \& Hargreaves, A. (Eds.) (1996). Teachers' professional lives. London: Falmer Press.

Khalid, F., Joyes, G., Ellison, L., \& Daud, M. Y. (2014). Factors influencing teachers' level of participation in online communities. Journal of International Education Studies, 7(13), 23-32. 
Khalid, F., Joyes, G., Ellison, L. \& Abdul Karim, A. (2013). Teachers' involvement in communities of practice: An implication with regard to the current approach of teachers' professional development of Malaysia. Asian Social Science, 19(16), 102-111.

Lave, J., \& Wenger, E. (1991). Situated learning: Legitimate peripheral participation. Cambridge: Cambridge University Press.

Maurer, T., \& Tarulli, B. A. (1994). Investigation of perceived environment, perceived outcomes and personal variables in relationship to voluntary development activity by employees. Journal of Applied Psychology, 79 (1), 3-14.

Miles, M.B., \& Huberman, A. M. (1994). An expanded source book: Qualitative data analysis (2nd ed.). Thousand Oaks, CA: Sage.

Nias, J. (1989). Primary Teachers Talking: A Study of Teaching as Work. New York: Routledge.

Srisrankulwong, S. (2005). Factors affecting teacher commitment in Thai private schools (Unpublished doctoral thesis), University of Nottingham, Nottingham, UK.

Sutton, R. E. (2000). The emotional experiences of teachers. Paper presented at the Annual Meeting of the American Educational Research Association, New Orleans, USA.

Wenger, E. (1998). Communities of practice: Learning, meaning, and identity. NY: Cambridge University Press. 